\title{
MEETING THE COMING ORGANIZATIONAL RISK CHALLENGES IN HUMAN RESOURCES
}

\section{Nebojsa Zakic ${ }^{28}$, Zeljko Papic ${ }^{29}$,Slobodan Radonjic ${ }^{30}$}

\begin{abstract}
The research presented in this paper concerns challenges of organizational risk in the field of human resources. Research goals are to determine the degree of importance and influence of human risks in order to achieve a more favorable environment for successful business. The empirical research has been conducted in Serbia during 2015, with a sample of 43 companies from the Processing industry. There were mathematical and statistical methods, multiple regression analysis and logistic regression used. Group's core results showed that over $80 \%$ of production companies are aware of the human resources risks and their importance for the business. The contribution of this paper is to prove the scientific significance of the upcoming risks of human resources establishing theoretical and empirical knowledge about the need to improve organization approach to managing these risks.
\end{abstract}

KEY WORDS: Human resources, Challenges, Organisational risks

JEL: J40,J20,J11

UDC: 005.334

005.96

\footnotetext{
${ }^{28}$ University Union Nikola Tesla, Belgrade, Serbia

${ }^{29}$ University of Kragujevac, Faculty of Technical Sciences, Cacak, Serbia

${ }^{30}$ National Tax Office, Belgrade, Serbia
} 


\section{Introduction}

Focusing on trends, potential changes in important assumptions, development, production companies are increasingly concentrate on minimizing the negative effects. Every firm in processing industry face various risks, which components determination is complex due to great heterogeneity and difficulty in separating business from owner / management (St- Pierre,Bahri, 2006). Globally, the high level of risk in all spehars of business, competition, talent, technology implementation, and R\&D, and insufficient level of return associated with them are present (International trade centre, 2009). According to Alpa (2005), the most pressing challenges they face in human resource spectrum are: high degree of employee turnover, management risk (Omolaja ,2015), inadequate management knowledge, shortage of skilled staff, market changes.

The function of risk management is becoming more and more a source of added value in the process of their strategic planning.

The growing awareness of the organization on the necessity of constant innovation, which is directly related to the conversation sector human resources (Sljivic, et al., 2015). New areas of risk that will be increasingly important in the coming period they are related to the organizational culture and the ability of employees to more effectively encourage customer retention development of their preferences, indicating a change in mindset and priorities for corporate leaders. It is essential for enterprises in production to be able to effectively manage risks to survive in highly competitive and slowing down economic conditions. The results show that these enterprises have inadequate resources and restricted know-how and new technologies (Jevtic, Vucekovic, 2014) generally confronted wideranging risks of human resources This paper with its research results supports the importance of monitoring of human resource risks in organizations and managment.

\section{Literature overview}

The traditional risk management considers risk as distinct threat focusing on downsizing the possible losses from risk events (Investopedia, 2013). According to Stephen, D. (2001) enterprise risk nanagement concerns the process through which business entities in different sectors can measure, govern, and monitor risks from all sources, in order to increase the value of shareholder stake in business. Thus, organizations need to adapt an integrated approach of risk management to mitigate human resource risks, (Olson, Desheng, 2008) to meet the requirement of and sustainability and business growth. As proposed by (COSO, 2004) the riks management in an processing firm would include further interrelated components which must be integrated with the management process: the internal environment comprises of the core philosophy of an enterprise, which influences the risk consciousness of its workforce; objective setting; recognizion of possible events that, if occur, will affect the organization, and then conclude whether those events exemplify prospects or whether they might negatively affect the organization`s ability to effectively implement strategy and accomplish goals; risk assessment and response; control activities; ICT information and ongoing monitoring 


\section{Research description}

The basis of this paper is the empirical research conducted on the territory of Serbia, in 2015 , in order to examine the attitudes of 43 companies from processing industry on organizational risk, especially those coming from the area of human resources.

The possible effects of various aspects of these risks on business performance, survival and development of the companies are explored.

\section{Methods used}

A methodological model questionnaire and interview guideline was developed in consultation with the applied methods of Social Research (Floyd, Fowler, 1984).

Analysis of results obtained from the survey were carried out on the basis of the hypothesis:

HO : The management of organizational risk in human resource sector has a positive impact on corporate performance of the processing companiy;

whose verification is determined by the degree of influence and the importance of managing organizational risks in the fields of human resources, in order to achieve a more favorable environment for successful enterprise business.

There are used methods of:

- descriptive statistical analysis of the observed data; determine the mean value and standard deviation;

- Statistical testing depending on individual variables sample

- The model of multiple regression analysis

- Logistic regression (Jaccard, 2001; Hessels, 2008) to find the model that best suited to data, from the information criterion (AIC) as a quantitative indicator of the general agreement obtained theoretical model in comparison to the empirical data set.

\section{Key research results}

Characteristics of the surveyed companies and their statistical indicators are shown in Table 1. The first column of Table 1 shows the attribute modalititete five characteristics, and observation of the first group of survey questions. Then, in the next column can be seen response value relative (percentage) frequencies. Finally, the last column of Table 1 contains the corresponding values of Pearson $\chi^{2}$ statistics, along with the corresponding $p$-value. These values indicate the significance of the difference between the theoretical value and the expected frequencies within one and the same modality (attributive) characteristics. 
Table 1: Main characteristics of interviewed processing companies

\begin{tabular}{|c|c|c|}
\hline Description & Persent & $\begin{array}{c}\chi^{2} \text {-statistics } \\
(p \text {-value })\end{array}$ \\
\hline \multicolumn{3}{|l|}{ Legal form } \\
\hline Private enterprise & $46,90 \%$ & \multirow{4}{*}{$\begin{array}{c}34,29^{* *} \\
(1,72 \mathrm{E}-07)\end{array}$} \\
\hline Part of holding & $23,01 \%$ & \\
\hline $\begin{array}{l}\text { Public } \\
\end{array}$ & $8,85 \%$ & \\
\hline Other & $21,24 \%$ & \\
\hline \multicolumn{3}{|l|}{ Position of nterviewed person } \\
\hline Owener & $30,97 \%$ & \multirow{4}{*}{$\begin{array}{c}2,65 \\
(0,4495)\end{array}$} \\
\hline Menager & $20,35 \%$ & \\
\hline Director & $23,89 \%$ & \\
\hline Consultant & $24,78 \%$ & \\
\hline \multicolumn{3}{|l|}{$\underline{\text { Revenue }}$} \\
\hline Les than $100.000 €$ & $26,55 \%$ & \multirow{4}{*}{$\begin{array}{c}0,805 \\
(0,8483)\end{array}$} \\
\hline $100.000-500.000 €$ & $27,43 \%$ & \\
\hline $500.000-2.000 .000 €$ & $23,89 \%$ & \\
\hline Higer than $2.000 .000 €$ & $22,12 \%$ & \\
\hline \multicolumn{3}{|l|}{$\underline{\text { Revenue realised }}$} \\
\hline $\begin{array}{l}\text { Inland } \\
\end{array}$ & $83,19 \%$ & 49,78 \\
\hline Foreign markets & $16,81 \%$ & $(1,72 \mathrm{E}-12)$ \\
\hline \multicolumn{3}{|c|}{$\underline{\text { Impact of organisational risks on revenues in }} \underline{\underline{2015} .}$} \\
\hline Revenues sustanability & $43,36 \%$ & \multirow{3}{*}{$\begin{array}{c}5,12 \\
(0,0775)\end{array}$} \\
\hline Revenues decrease & $28,32 \%$ & \\
\hline Revenues increase & $28,32 \%$ & \\
\hline
\end{tabular}

${ }^{*} \mathrm{p}<0.05,{ }^{* *} \mathrm{p}<0.01$

Based on the observed values of characteristics relating to the legal form of the enterprises surveyed, almost half of the sample are private independent enterprises form processing sector. Observing the structure of positions of respondents within companies, it can be seen their relatively equal representation in the sample. This fact was formally confirmed by the relatively small value of the Pearson statistic $(\chi 2=2.65)$. The next memorial describes the level of income of the enterprises surveyed in 2015. It is observed a relatively equal representation of companies within the sample, ie. represented in almost equal numbers of companies with different levels of income. This is confirmed by statistics, the value of Pearson $\left(\chi_{2}=0.805\right)$, which compared with other factors here has by far the lowest value. Next, follow label that describes the sources of income of the enterprises surveyed. Here is domantan number of those revenues realized within the home country (more than $80 \%$ of the sample). Only a small portion, less than $17 \%$ of companies their income comes from the business abroad.

In the last survey question companies answered how the various organizational /human resource risks impact the amount of their income in 2015. Slightly less than half of the 
respondents have confirmed this effect, stated that the influence of different organizational risks led to the sustainability of their income. Finally, an equal number of surveyed companies argued that the impact of the risks highlighted the reduction of actual sales, and believes that the risks are increasing their impact on revenue in 2015.

The second part analyzes the basic characteristics of surveyed companies determined the interdependence of their main activities in terms of the three above-mentioned characteristics: revenue realized in 2015, sources of income, as well as the risk impact on revenues. For this purpose, it is used another form of the Pearson $\chi 2$ test, the so-called. test characteristics independence, which describes in detail the theoretical principles of the previous section.

Table 2: Number of observations, the mean value and standard deviation of human resource risks in processing companies

\begin{tabular}{clccc}
\hline Variable & $\begin{array}{c}\text { Kind of risk enterprises } \\
\text { monitor }\end{array}$ & $\begin{array}{c}\text { No.positiv } \\
\mathbf{e} \\
\text { responses }\end{array}$ & $\begin{array}{c}\text { Proportio } \\
\mathbf{n}(\boldsymbol{p})\end{array}$ & $\begin{array}{c}\text { Standard } \\
\text { dev. }\end{array}$ \\
\hline$X_{1}$ & Human resource risks & 41 & 0,3628 & 0,2312 \\
$X_{11}$ & Other & 2 & 0,0177 & 0,0174 \\
\hline
\end{tabular}

Table 3: Realized value, attitude scale (OR), legit function and the estimated value of coefficient of logistic regression (processing companies).

\begin{tabular}{|c|c|c|c|c|}
\hline Variable & Kind of risks & OR & $\begin{array}{l}\text { Regression } \\
\text { coeff. }\end{array}$ & $\begin{array}{c}\text { Standard } \\
\text { error }\end{array}$ \\
\hline Regresiona konstanta & & & 0,51031 & $6,76 \mathrm{E}-02$ \\
\hline$X_{6}$ & Human resource risks & 0,5694 & 0,03253 & $5,66 \mathrm{E}-02$ \\
\hline$X_{7}$ & Organisational risks & 0,5694 & 0,09968 & $5,51 \mathrm{E}-02$ \\
\hline Total error $(Q)$ : & 0,2761 & & & \\
\hline $\begin{array}{l}\text { Determination coeff. } \\
\left(R^{2}\right):\end{array}$ & 0,8260 & & & \\
\hline$A I C:$ & 42,281 & & & \\
\hline
\end{tabular}

In the second part of the statistical analysis on types of human resource risks is described bz mutual influence of dichotomous variables (X1, X2, ..., X10), describing: the participation of the enterprises surveyed in managing organizational risk, compared to the level of their earned income in the previous 2015 . year. Based on the dichotomous nature of the variables that describe the above internal risks which potentially managed surveyed entities, heir interconnectedness and dynamic structure, described by logistic regression analysis, showen as an appropriately chosen model (Figure 1). 


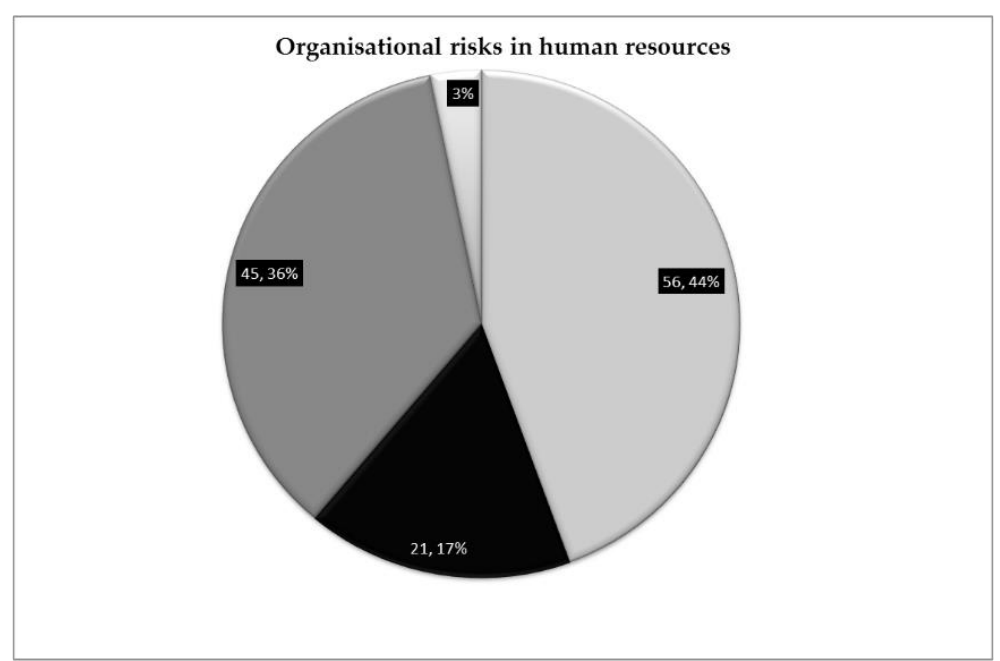

Figure 1:Organisational risks in human resources of processing companies

Legend: $54,44 \%=$ Capabilities and availability of employees; $45,36 \%=$ Omissions in the work of employed; $23,17 \%=$ Job security; $3 \%=$ Other.

For the purpose to see the effect of different human resource operations as prospective risk of the companies, it has been formed part of the questionnaire with six specific survey questions (dichotomous variables). The values of absolute frequency and therefore the proportion of positive responses of respondents are by far, (Figure 2), the most pronounced in fluctuation risk / retention of employees. Followed by confirmation responses influence the risk of a training plan that would be tailored to the needs and the time of the company, while the frequency of other risk types of human resources, such as the number of abandoned and replaced jobs, often leaving key personnel, the number of legal labor disputes against the company is much less frequent.

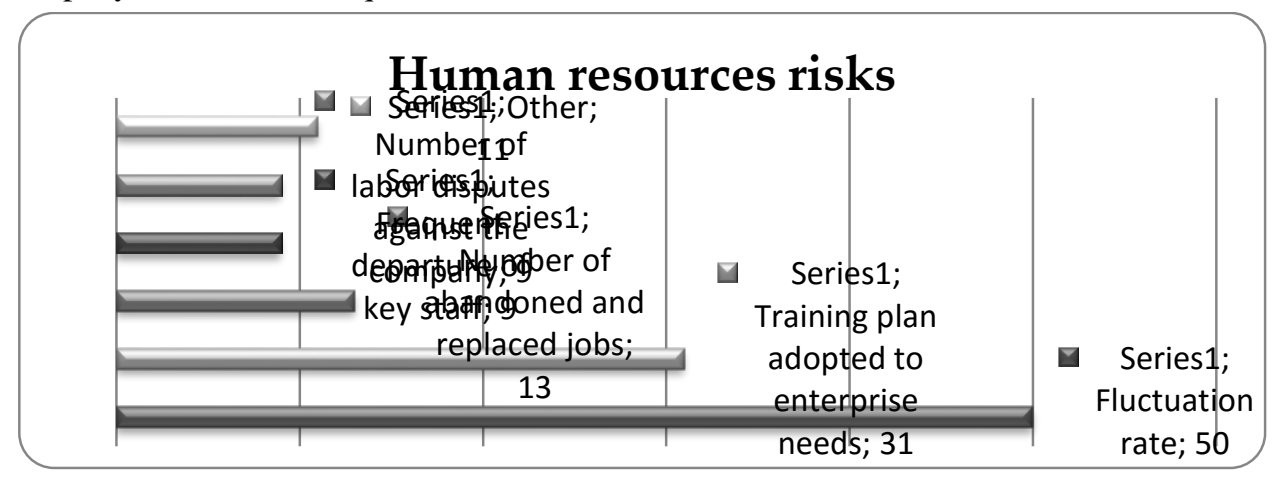

Figure 2: The impact of human resource risks, postitive responses of the processing industry firms

Similar conclusions can be reached by statistical analysis of estimation of regression coefficients which, together with the OR values, and the corresponding standard errors of assessment, are shown in Table 3 . Here are obtained (mostly) positive values, which confirms the validity of the hypothesis A0 to manage organization risk in the field of human resources 
has a positive impact on the operations of the companies. The only negative value of the estimated regression coefficient corresponds precisely to risk aspct- fluctuations rate, and retaining employees who have the highest incidence of positive respondents' answers.

The quality of the resulting logistic regression model confirmed the values of appropriate quantitative indicators.

Table 3: Realized value. attitude scale (OR), legit function and the estimated value of coefficient of logistic regression, all researached aspects of human resource risk

\begin{tabular}{llrrr}
\hline \multicolumn{2}{c}{ Variables } & OR & $\begin{array}{c}\text { Regression } \\
\text { coeff. }\end{array}$ & $\begin{array}{c}\text { Standard } \\
\text { error }\end{array}$ \\
\hline \multicolumn{2}{l}{ Regresiona konstanta } & & 0,4731 & $4,12 \mathrm{E}-02$ \\
$X_{1}$ & Fluctuation rate & 0,7937 & $-0,0644$ & $5,18 \mathrm{E}-02$ \\
$X_{2}$ & Training plan adopted to enterprise needs & 0,3780 & 0,0153 & $6,03 \mathrm{E}-02$ \\
$X_{3}$ & No.of abandonedt and replaced jobs & 0,1300 & 0,1140 & $1,00 \mathrm{E}-01$ \\
$X_{4}$ & Frequent quit of key staff & 0,0865 & 0,1399 & $1,16 \mathrm{E}-01$ \\
$X_{5}$ & No.of labor disputes against the enterprise & 0,0865 & 0,1806 & $9,87 \mathrm{E}-02$ \\
$X_{6}$ & Other & 0,1078 & 0,0154 & $1,05 \mathrm{E}-01$ \\
\hline Total error $(Q):$ & & & \\
Determination coeff. & $\mathbf{0 , 2 6 6 8}$ & & & \\
$\left(R^{2}\right):$ & $\mathbf{0 , 8 6 7 7}$ & & & \\
AIC: & $\mathbf{3 0 , 8 4 0}$ & & & \\
\hline
\end{tabular}

\section{Conclusions}

Operational risk is present in the everyday functions and services of the organization. Accordingly, these risks may arise from the risks of movement and quality of human resources, property, infomacionih systems or processes involved in providing the expected or necessary products or services.

The research results presented in this paper have proven the validity of the hypothesis. Those organizational risks in the field of human resources are of great impact on sustainability and gow of processing companies.

Oposite of the current practice where tha most risk activities tend to be understood reactively, thereby reducing the ability of the available resources to mitigate the risk, in future modern business a structured approach to Enterprise Risk Management would be needed, day to day operations and organizational alignment in the field of human resources to the company's mission and objectives. Through effective human resource risk identification, assessment and mitigation, a processing company would be able in global environment to unlock the valuable upside of risk and create competitive advantage, inevitability, safety, efficacy, flexibility, self-assurance and create value. 


\section{References}

[1] Alpa A.Virdi, et al., (2005). Risk Management among SMEs - Executive report. Institute of Chartered Accountants in England and Wales, Consultation and Research Center.

[2] COSO (Committee of Sponsoring Organizations of the Treadway Commission) (2004). Enterprise Risk Management- Integrated Framework: Application Technique. 2.

[3] David, L. Olson \& Desheng, D. Wu., (2008). Financial Engineering and Risk Management - Enterprise Risk Management, Volume 1. Singapore: World Scientific Publishing Co. Pte. Ltd. pp. 3 -8.

[4] Floyd J. and Fowler, (1984). Applied Social research Methods series, Volume 1, Sage publications, Beverly Hills, at: http://www.surveysystem.com/sscalc.htm.

[5] International Trade Centre. (2009). How to access trade finance a guide for exporting SMEs. Geneva: International Trade Centre.

[6] Investopedia.com (2009). The Evolution of Enterprise Risk Management. Accessed 30.04.2013. Published 26.02.2009.

[7] Jevtic,B., Vucekovic,M. Radulovic,D.(2014)“Technology Innovations-Evidence form Serbia”, International Review, No.3-4/2014, pp 27, Faaculty of Business Economics and Entrepreneurhsip, Belgrade, Serbia

[8] Omolaja, M. (2015) "Advantages and disadvantages of line and staff style of organisations", International Review, No.3-4/2015, pp 15, Faaculty of Business Economics and Entrepreneurhsip, Belgrade, Serbia

[9] Sljivic,S., Skorup,S., Vukadinovic P.(2015). "Mangement control in modern organisations" ,International Review, No.3-4/2015, pp 39, Faaculty of Business Economics and Entrepreneurhsip, Belgrade, Serbia

[10] Stephen P. D'Arcy, (2001). Enterprise Risk Management, in Journal of Risk Management of Korea. Vol. 12, No.1. 25 pp.

[11] St-Pierre, J., \& Bahri, M., (2006). The use of the accounting beta as an overall risk indicator for unlisted companies: Journal of Small Business and Enterprise Development, Volume 13(4):546-561.

\section{Article history:}

- Received 15 March 2016

- $\quad$ Accepted 26 April 2016 